\title{
Author Correction: Flexibility and intensity of global water use
}

Yue Qin (D), Nathaniel D. Mueller, Stefan Siebert (D), Robert B. Jackson (1), Amir AghaKouchak (D), Julie B. Zimmerman, Dan Tong, Chaopeng Hong and Steven J. Davis

Correction to: Nature Sustainability https://doi.org/10.1038/s41893-019-0294-2, published online 3 June 2019.

In the version of this Analysis originally published, in the section 'Trends in global water demand', the percentage increase in agricultural area equipped for irrigation was incorrect: the text 'rose by $48 \%$ from 270 to $400 \times 10^{6}$ ha' should have read 'rose by $50 \%$ from 220 to $330 \times 10^{6}$ ha'; this has now been corrected.

Published online: 19 June 2019

https://doi.org/10.1038/s41893-019-0337-8 